\section{Autologous translocation of the choroid and RPE in age-related macular degeneration: 1 -year follow-up in 30 patients and recommendations for patient selection}

FMA Heussen ${ }^{1,4}$, NF Fawzy ${ }^{1,4}$, S Joeres ${ }^{1}$, A Lux ${ }^{1,2}$, K Maaijwee $^{3}$, JCv Meurs ${ }^{3}$, B Kirchhof $^{1}$ and AM Joussen ${ }^{1,2}$

\begin{abstract}
Aim To evaluate the long-term (1 year) functional and anatomical outcome of autologous translocation of peripheral choroid and retinal pigment epithelium (RPE) in 30 patients with age-related macular degeneration (AMD).

Methods After the extraction of the neovascular complex, an autologous peripheral full-thickness graft of RPE and choroid was positioned under the macula. Functional tests included ETDRS vision, reading (Radner test), and microperimetry (scanning laser ophthalmoscope). Fluorescein, indocyanine green angiography, and autofluorescence were monitored.

Results Preoperative visual acuity ranged from $20 / 40$ to $20 / 800(0.3-1.6 \log$ MAR). Vision ranged from $20 / 25$ to LP (0.1-2.1 $\log$ MAR) 1 year after surgery, with stabilization in six eyes, an increase in five eyes, and a decrease in 19 eyes. Deterioration mostly occurred within the first 3 months after surgery. In patients who demonstrated vascularization of the graft after 3 months, this persisted up to 12 months as did fixation when initially stable.

Autofluorescence decreased significantly from 6 to 12 months postoperatively. Eleven cases showed a recurrence of choroidal neovascularization (CNV) within this period. Conclusion Patch translocation results in a viable graft. There is no evidence of graft failure within a 1-year follow-up. Nevertheless, there is risk for late CNV formation originating from the edges of the
\end{abstract}

excision side of the $\mathrm{CNV}$ and growing peripheral to the graft.

Eye (2008) 22, 799-807; doi:10.1038/sj.eye.6702823; published online 20 July 2007

Keywords: age-related macular degeneration; translocation; RPE; choriod

\section{Introduction}

Age-related macular degeneration (AMD) is the major cause for central visual loss in the elderly population. Although recent pharmacological regimes for the first time promise improvement of central vision, ${ }^{1,2}$ most therapies so far were merely able to slow down but not stop progression of the disease. ${ }^{3}$ Even though the vast majority of patients will be treated by pharmacological means in the future, it is possible that we will continue to see advanced lesions in first eyes or patients with large subretinal haemorrhages that are not eligible for treatment, for example by vascular endothelial growth factor (VEGF) inhibitors.

It is known that surgical extraction of the choroidal neovascularization (CNV) in these patients is technically feasible; ${ }^{4,5}$ however, it did not improve nor preserve visual acuity (VA) over 24 months in randomized trials. ${ }^{6}$ Peyman first suggested translocation of peripheral choroid and retinal pigment epithelium (RPE) in order to supplement transplanted pigment epithelium with the underlaying intact Bruch's membrane and choroid. ${ }^{7}$ Later on, Aylward and
${ }^{1}$ Department of Vitreoretinal Surgery, Center of Ophthalmology, University of Cologne, Cologne, Germany

${ }^{2}$ Department of Ophthalmology, University of Duesseldorf, Duesseldorf, Germany

${ }^{3}$ The Rotterdam Eye Hospital, Rotterdam, The Netherlands

Correspondence: AM Joussen, Department of Ophthalmology, University of Duesseldorf Moorenstrasse 5, 40225 Düsseldorf, Germany Tel: + 4921181 17320; Fax: + 492118116342 .

E-mail: Joussena@ googlemail.com

${ }^{4}$ These authors contributed equally to this study and should be considered first authors

Received: 10 September 2006

Accepted: 8 March 2007 Published online: 20 July 2007 
van Meurs demonstrated the clinical feasibility of the new technique. ${ }^{8,9}$ We have recently reported on the functional results and complication profile in our first series. $^{10}$

Yet, any treatment has to be judged by its long-term benefits and despite of initial encouraging results with RPE and iris pigment epithelium (IPE) transplantation techniques, ${ }^{11,12}$ long-term results demonstrated a preservation of foveal function only on a low level, but no improvement in VA. ${ }^{13,14}$ Here, we assessed whether the initial results of patch translocation remain stable in the long-term follow-up.

\section{Patients and methods}

All patients had visual loss because of AMD: one eye with classic membrane, one eye with mixed membrane, one eye with RAP II, seven eyes with occult membranes, 13 eyes with pigment epithelial detachment, two eyes with rupture of the RPE, and five eyes with massive subretinal bleeding were included. We selected patients with relatively large subfoveal lesions or poorly demarcated lesions to whom laser photocoagulation or photodynamic therapy was judged to be unsuitable or did not show improvement. Angiographic clues of lesion activity (leakage) were demanded in addition to a history of recent loss of reading vision ( $<3$ months). Eligible eyes had best-corrected visual acuity (BCVA) corresponding to Snellen fractions of 20/40-20/800 (VA scores of 68-4).

The study is consistent with the Declaration of Helsinki Principles and was approved by the Ethics Committee of the Medical Faculty of the University of Cologne, Germany. Before inclusion, written informed consent was obtained form each patient after explanation of the nature of the study.

\section{Surgery}

The surgical procedure comprised a standard three-port pars plana vitrectomy and detachment of the posterior hyaloid. Almost all patients required a surgically induced posterior vitreous detachment. The retina was separated from the neovascular lesion by subretinal injection of balanced salt solution (BSS) using a glass pipette.

The retinotomy was in the vascular arcade in all patients and was enlarged by two radial cuts with a vitreous scissors. The total opening was about two-thirds of a disc diameter, to allow the folded patch to be inserted but as small as possible to prevent proliferative vitretinopathy (PVR) development.

After enlarging the retinotomy site, the neovascular membrane was removed from the subretinal space using a modified Thomas' forceps. All instruments used were 27 gauge instruments. The excision site of the graft was chosen outside the vascular arcade and demarcated by laser photocoagulation. After removal of the overlying retina, the graft was mobilized from the sclera, grasped at the choroidal side, and inserted underneath the macula through the retinotomy. As vitreous tamponade, either SF6 20\%, silicone oil (5000 cSt), or heavy silicone oil (Densiron ${ }^{\circledR}$, Fluoron GmbH, Neu-Ulm, Germany) was used. Out of this series, a total of 15 patients received a primary gas tamponade. Eight patients were treated with silicone oil 5000 as a primary tamponading agent and the remaining seven patients received a primary Densiron tamponade.

After a minimum of 3 months, the silicone oil was removed. Details of the technique have been published. ${ }^{10}$

\section{Patient follow-up}

Eyes were examined before surgery, 3 months, 6 months, and 1 year postoperatively. Patients requiring revisional surgery were followed up for 6 months and 1 year thereafter.

The regular scheduled follow-up visit included the following:

- a protocol refraction

- BCVA measurement according to $\mathrm{ETDRS}^{10}$

- reading performance using the Radner test ${ }^{15,16}$

- ophthalmoscopic examination

- colour fundus photography

- autofluorescence measurement

- fluorescein (FA) and indocyanine green (ICG) angiography

- fixation testing and fundus-controlled microperimetry

In short, fundus autofluorescence was measured with the Heidelberg retina angiograph (HRA II, Heidelberg Engineering $\mathrm{GmbH}$, Dossenheim, Germany). To exclude influence of image brightness on autofluorescence measurements, grey-scale values of the patch area were compared with autofluorescence in a pristine area outside the patch within the same eye.

FA and ICG angiography were performed using the HRA-II to visualize perfusion of the transplant and to recognize eventual recurrent CNV. Grading of the angiographies was done according to the TAP-study criteria. ${ }^{17}$

Functionality of the central visual field was assessed by static threshold fundus microperimetry with the scanning laser ophthalmoscope (Rodenstock $\mathrm{GmbH}$, Munich, Germany; software version 2.0). ${ }^{10}$ A total of 240 stimuli (comparable with Goldmann III) with three different light intensities were presented for 120 milliseconds each with manual fundus tracking. 
From the cloud of fixation points, the centre of gravity was calculated, which equals the preferred retinal locus (PRL). The deviation from this PRL was used to determine fixation stability with $1^{\circ}$ defined as stable and variations between 1 and $3^{\circ}$ as predominantly stable. ${ }^{10}$ Owing to a minimum requirement of VA, only 19 out of 30 patients were examined 1 year postoperatively. For the remaining eyes, a less demanding test was performed using the Foerster cross (Geuder AG, Heidelberg, Germany) to determine the mean fixation point. ${ }^{10}$

\section{Statistical analysis}

We performed a 'full analysis set'. The parameters of interest for statistical evaluation - namely VA ( $\log$ MAR), reading acuity, and fixation stability - were analyzed based on the respective measurement at the last examination. Analyses were adjusted to the baseline VAs. Because of the various baseline values and follow-up periods, these two factors were considered to be covariates in the statistical analysis. Thus, a three-factor analysis of covariance model (between the factors: treatment groups, covariable baseline measurement, and follow-up period) was fitted to the data of the six parameters listed. $P<0.05$, as a result of the statistical two-sided tests, was considered significant. Furthermore, the data were described by appropriate statistical measures. Computations were conducted on computer (SAS, version 8 (proc means, mixed, glm) for Windows XP; SAS, Cary, NC, USA).

\section{Results}

Far vision and reading acuity: - changes between 6 months and 1 year

Mean preoperative VA was $0.8 \pm 0.3 \log$ MAR and $1.1 \pm 0.5 \log$ MAR at 6 and 12 month follow-up. Between 6 and 12 months, distance acuity remained stable ( \pm 1 line) or improved in 23 out of 28 patients $(82 \%)$ (Figure 1). Figure 2 shows a patient with a continuous improvement in distant VA. At the 6-month follow-up, vision improved in contrast to the preoperative value from 1.0 to $0.9 \log$ MAR. Further improvement was noted between 6 months and 1 year with VA values of $0.8 \log$ MAR (Figure 2). There was an improvement between 6 months ( $1.4 \log$ RAD) and 1 year $(1.1 \log$ RAD) in reading acuity as determined by Radner test.

All patients, who were able to read at 6-month follow-up kept this ability up to 12-month examination. Four patients achieved reading level postoperatively for the first time, namely after 6 to 12 month. Mean reading ability was $0.9 \pm 0.2 \log \operatorname{RAD}(n=23)$ preoperatively, $0.9 \pm 0.4 \log \operatorname{RAD}(n=9)$ at 6 -month, and
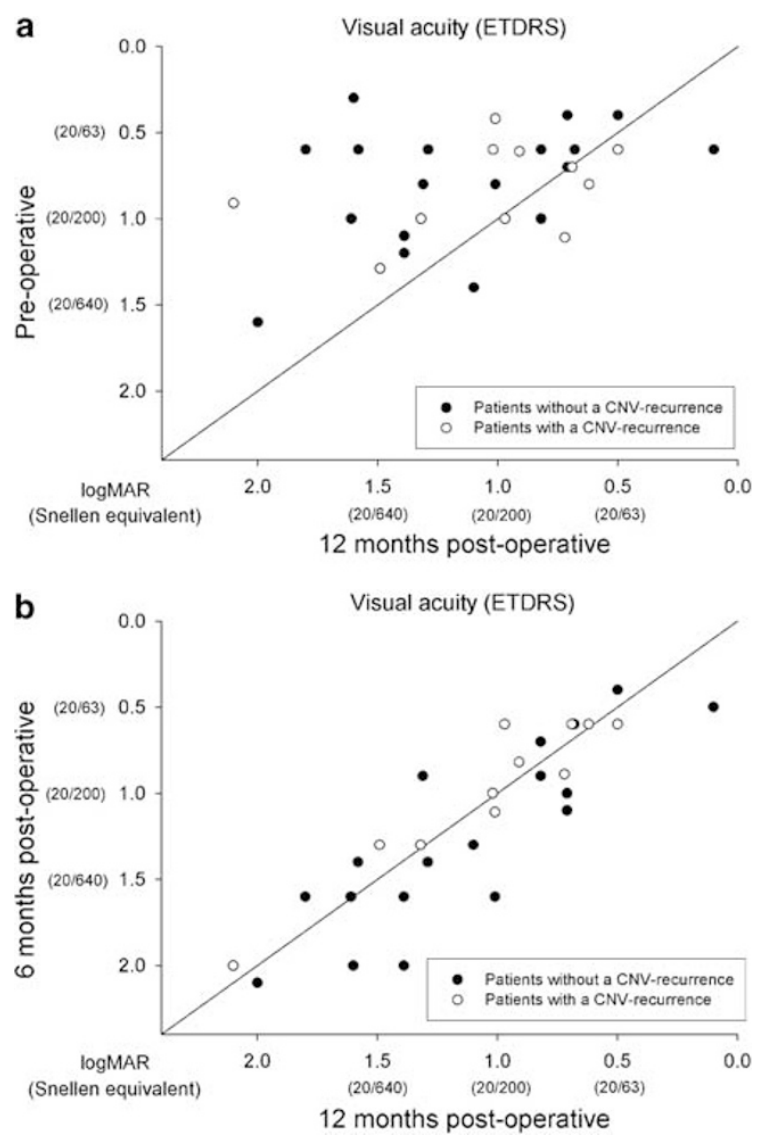

Figure 1 (a) Far vision before surgery compared with 1-year follow-up. Few patients gained vision. Deterioration of VA is independent of $\mathrm{CNV}$ recurrence outside of the graft, but rather dependent on intra- and postoperative complications. (b) Far vision after 6 months compared with after 1-year.

$1.0 \pm 0.3 \log \operatorname{RAD}(n=13)$ at 12 -month follow-up

(Figure 3).

There was an increase in both VA as well as reading vision in patient no.11 as demonstrated in Figure 4. Distant vision increased from 0.8 to $0.6 \log$ MAR and reading acuity from 1.0 to $0.7 \log$ MAR. Despite the recurrence of a CNV between 6 months and 1 year, neither far acuity nor reading vision was affected, near VA increased even from 0.7 to $0.5 \log$ RAD.

Figure 5 shows a patient with initially low reading ability (1.4 log RAD) and distant VA (1.3 log MAR). A recurrent $\mathrm{CNV}$ was diagnosed at 1 year. Far VA decreased from 1.3 to $1.5 \log$ MAR. Preoperative reading ability was lost.

\section{Autofluorescence of the graft}

Autofluorescence images were taken in 23 eyes at 1-year follow-up and were compared with 24 images eligible for evaluation at 6-month follow-up. Autofluorescence was homogenous throughout the patch and correlated neither 

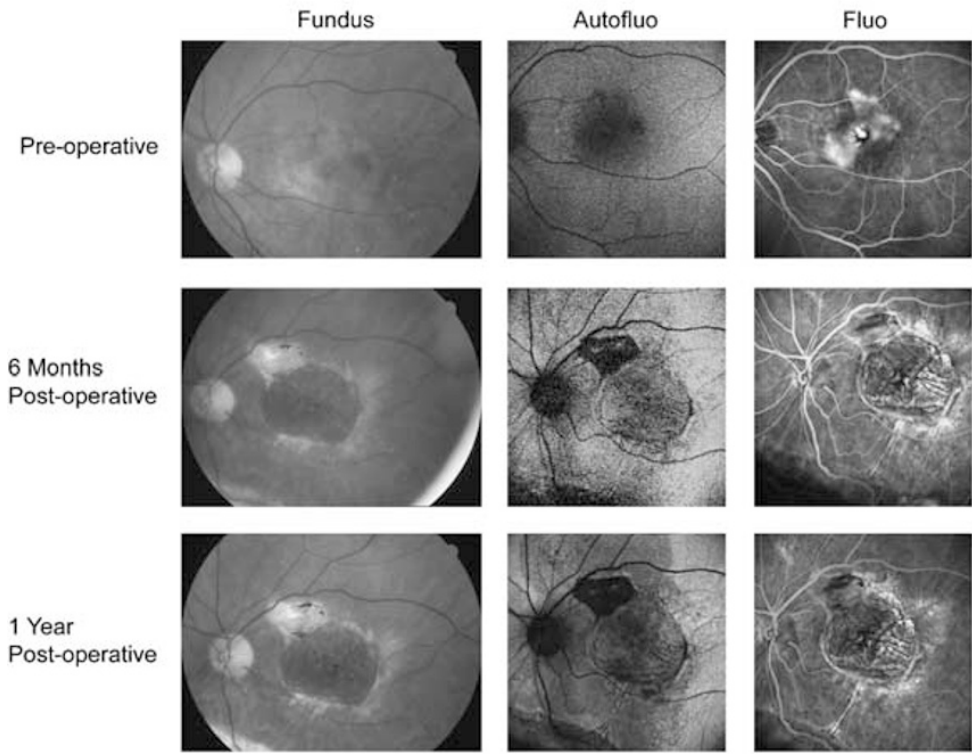
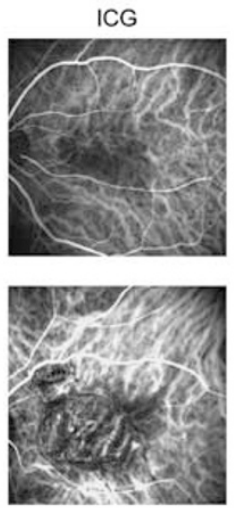

Visual acuity

(logMAR)

(Snellen)

Reading acuity

(logRAD)

(Snellen)

1.0

$(20 / 200)$

0.8

$(20 / 125)$

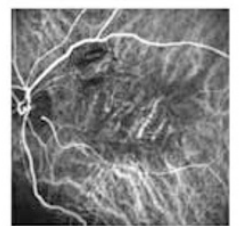

0.9

(20/160)

14

(20/500)

0.8

(20/125)

Figure 2 This figure shows patient no. 27. There were no intraoperative complications, postoperative massive subretinal bleeding occurred shortly after surgery. No further complications were noted. One year after patch surgery, VA as well as reading acuity improved in comparison with the 6-month follow-up. The preoperative reading acuity is yet to be reached, whereas preoperative VA is already exceeded. Angiographic appearance of the fundus is rather positive with no signs of a CNV recurrence or large fibrosis (OCT data on patch surgery is in press).

to VA nor vascularization of the graft. All combinations of VA and autofluorescence intensity were found including patients with decreasing VA and increasing autofluorescence after 1 year and vice versa. There was a slight reduction of autofluorescence over a period of 1 year $(P<0.05$, owing to the low number of eyes eligible for autofluorescence analysis; however, power of the t-test was only 0.603 (desired power: 0.800)) (Figure 6).

\section{Microperimetry}

When comparing microperimetry after 6 months with the 12-month follow-up data, there was no change in any of the patients. The mean light sensitivity of the patch did neither increase nor decrease to a statistically relevant extent and did not correlate with the development of VA nor to CNV recurrence (Figure 7). The size of absolute scotoma within the measured field remained stable.

\section{Fixation}

At 1 year, eyes with VA of $1.0 \log$ MAR and better showed either stable or predominantly stable fixation (12 out of 13 eyes). Of the 17 eyes with VA worse than $1.0 \log$ MAR, fixation was evaluated for 11 eyes. Fixation was stable on the patch in only three of these cases.

A comparison between fixation results at 6 months and at 1 year shows that all patients with stable fixation at
6 months remained either stable or predominantly stable until the 1-year examination. Four eyes, which showed unstable fixation at 6 months, were examined after 1 year and improved to predominantly stable.

\section{Postoperative complications}

In general, the clinical appearance of the patch graft at the 1-year follow-up showed no noticeable change compared with the 6-month follow-up. ${ }^{10}$ Interestingly, no additional PVR detachments occurred between 6 and 12 months follow-up. Only one patient developed a large macular pucker that required surgical revision.

Decentration of the patch was present in three cases. One patient did not demonstrate vascularization of the graft throughout the follow-up.

Eleven CNV recurrences were detected between 6 months and 1 year after surgery, four of which were treated immediately by laser coagulation. CNV recurrences formed independent of the preoperative lesion type. Two patients underwent laser coagulation because of leakage albeit no definite CNV formation. No further cases of massive subretinal haemorrhage, hyaloid bleeding, or vascularization failure were seen. Mean VA changes from baseline were compared for eyes with and without $\mathrm{CNV}$ recurrences at each examination time. Between 6 and 12 months after patch surgery, eyes with a $\mathrm{CNV}$ recurrence lost a mean of two to three letters, 

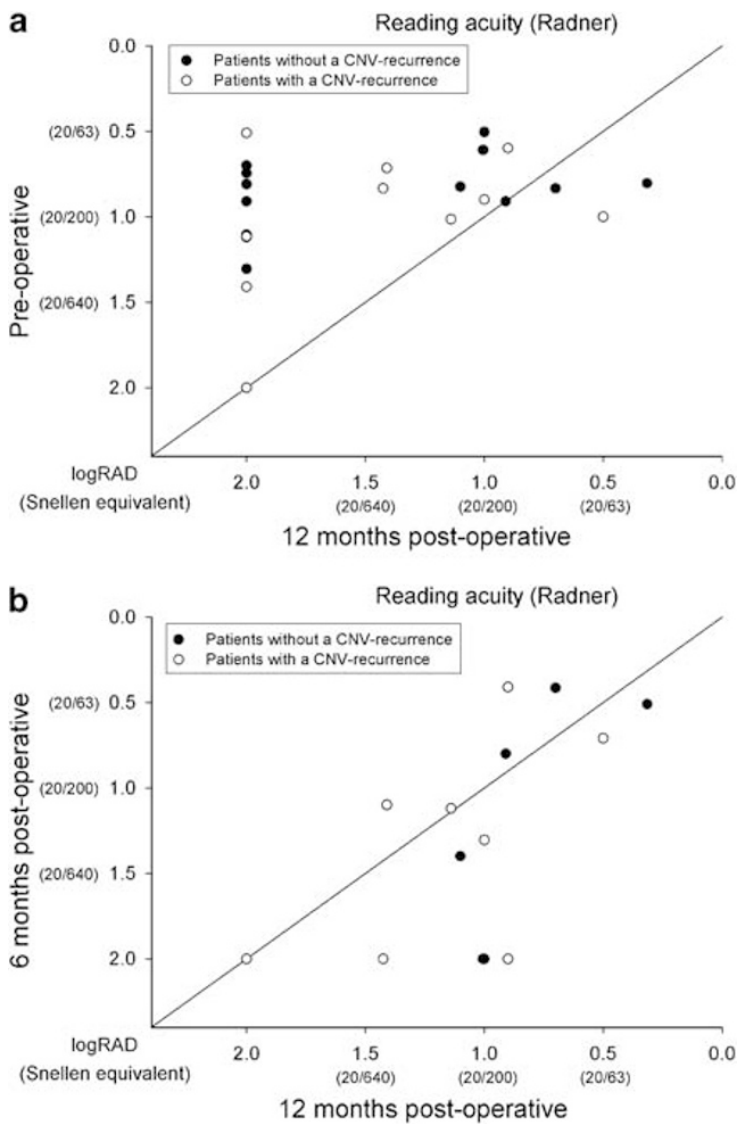

Figure 3 (a) Reading acuity before surgery compared with 1-year follow-up. Few patients gained vision. Deterioration of VA is independent of CNV recurrence outside of the graft, but rather dependent on intra- and postoperative complications. (b) Reading acuity after 6 months compared with after 1 year. whereas eyes without recurrence gained two letters. Thus, VA at that stage was independent of CNV formation (Supplementary Information).

\section{Discussion}

We report here on the 1-year follow-up of 30 patients after translocation of a free graft of RPE and choroid. We have previously found that patients with preoperative stable fixation and good VA are likely to maintain stable fixation and good VA also after surgery. ${ }^{10}$ The current data confirm this hypothesis in a long-term follow-up. Between 6 and 12 months, there was almost no change in VA. Decrease of VA mostly occurred within the first 3 months after surgery and was related to surgical or postoperative complications. There was a mean increase of $0.1 \log$ MAR from 3 to 12 months. This demonstrates that in contrast to mere membrane extraction or IPE translocation, ${ }^{13,20}$ sheet translocation achieves an overall stabilization of the preoperative level of VA. Improvement of VA is possible even later during the follow-up. A similar postoperative improvement was reported in a series of 61 patients followed up for 12 months after $360^{\circ}$ macular translocation. ${ }^{21}$ The overall better functional results of the macular translocation series compared with our series could be explained by a lesser complication rate, probably caused by a further evolved surgical technique.

We demonstrate further that all major complications occur within the early postoperative period.

Vascularization of the graft, if achieved early in the

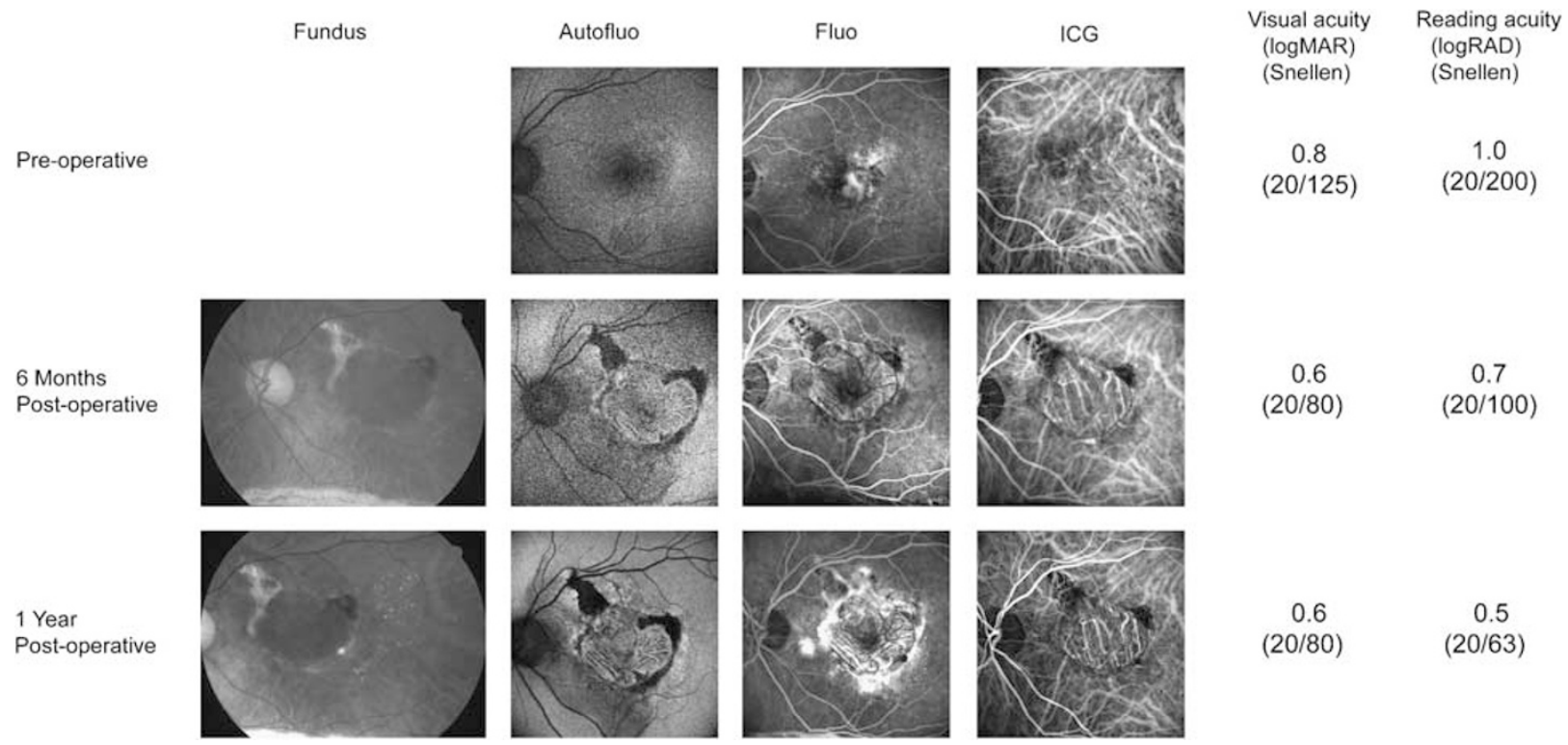

Figure 4 Between 6 and 12 months after patch surgery, patient no. 11 presented with a CNV recurrence that did not affect the good development of visual and reading acuity. Apart from this recurrence, the eye remained complication free. Autofluorescence and vascularization of the patch are still good, as can be seen in the angiographic pictures. 

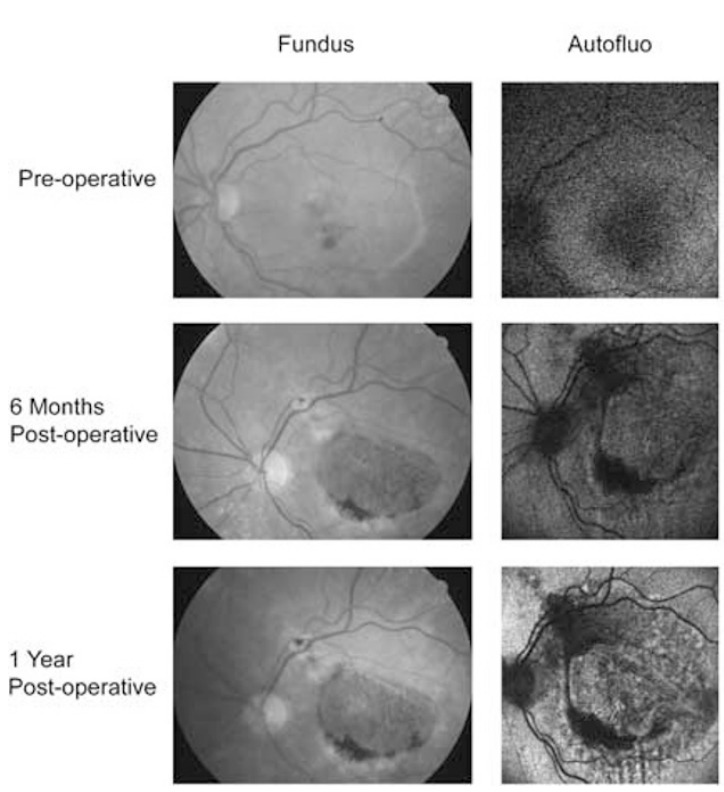

early Fluo
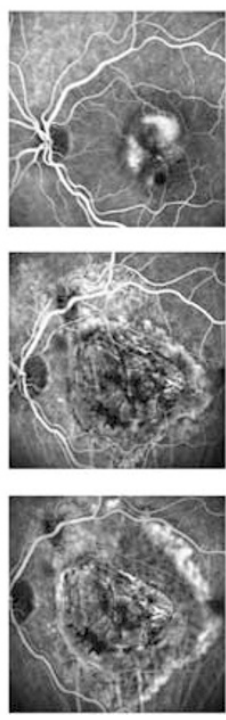

late Fluo
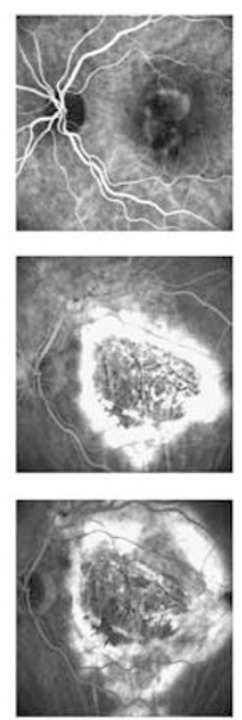
(logMAR)

(Snellen)

1.3

$(20 / 400)$ $(20 / 500)$

1.3

$(20 / 400)$

not possible

1.5

$(20 / 640)$ $(\log R A D)$

(Snellen)

.4

(1)

Reading acuity

Figure 5 These angiographies demonstrate the development of a large CNV recurrence in patient no. 18. At the 6-month follow-up, a fluorescein leakage around the patch was seen. Six months later, a prominent CNV recurrence was diagnosed. Visual/reading acuity never recovered after patch surgery and is still very low. Autofluorescence of the patch was visible throughout the whole year of follow-up examinations.

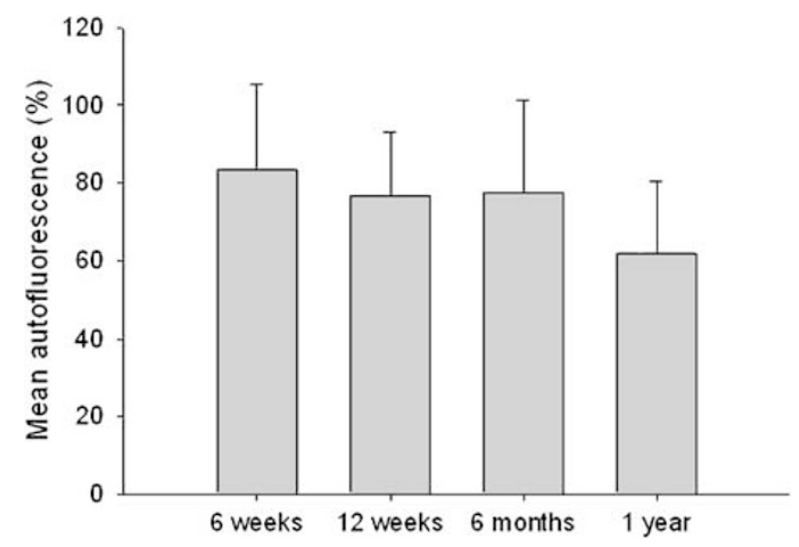

Figure 6 Autofluorescence of the graft compared with autofluorescence in an area outside of the macula remains stable up to 6 months after operation. From 6 month to 1 year after surgery, we observed a significant decrease in autofluorescence $(P=0.02)$.

course, remained stable throughout the follow-up as did fixation stability in contrast to a slight deterioration of autofluorescence. In contrast, autofluorescence decreased from 6 to 12 month post-translocation, but diminished autofluorescence was not paralleled by loss in VA. It appears that autofluorescence is a poor predictor of macular function. Earlier attempts of pigment cell translocation using cell suspensions could not find autofluorescence related to the transplants at all. ${ }^{13,14}$ Autofluorescence may be greater in the periphery
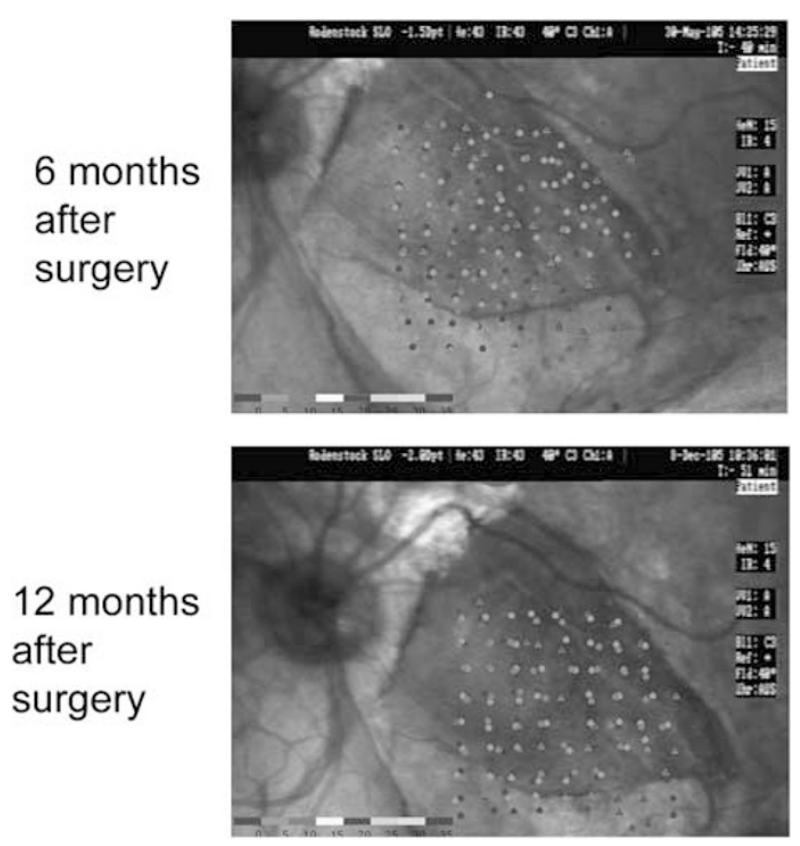

Figure 7 Microperimetry of patient no.18 (same patient as in Figure 4) 6 months and 12 months after surgery demonstrated sensitivity in the area of the graft in contrast to an absolute scotoma in the area of atrophy surrounding the graft.

because the disc-lipofuscin load may be greater there, in line with the increased rod density. Furthermore, the photoreceptors around the fovea will be damaged by AMD and this might represent a re-establishment of disc turnover status quo. 
After macular translocation, recurrent RPE atrophy occurs early in dry AMD but is unlikely in neovascular AMD. ${ }^{18}$ A longer follow-up is needed to know whether transplant failure is to be expected after as long as 5 to 6 years, as reports in patients with juxtamacular graft is sporadic. $^{19}$

We classified any postoperative retinal detachment as PVR based, assuming that in a vitrectomized eye the retina usually does not detach from a mere retinal hole without traction and the eyes operated on are not 'normal eyes' because the RPE is not pumping properly and there may even be an initial exudative component from within the graft site. Detachment may then progress to PVR as RPE cells escape. In our series in eight patients (26\%), PVR with obvious vireo-retinal traction was involved. After $360^{\circ}$, full macular translocation $19 \%$ PVR was reported. ${ }^{22}$ In the submacular surgery trial (SST), 27 eyes (16\%) in the surgical arm, compared with three eyes $(2 \%)$ in the observation arm presented with retinal detachments. ${ }^{20}$ A lower risk was shown in other reports. ${ }^{21,23}$ Our much higher PVR rate may reflect the wound-healing response of a choroidectomy near the vitreous base. It may be improved by more meticulous shaving of the vitreous base and a prophylactic $360^{\circ}$ laser cerclage. However, we report here the first consecutive patients, using a new surgical technique that reflects in part the surgeons learning curve. ${ }^{10}$

We have encountered postoperative subretinal haemorrhages in $15(50 \%)$ patients. This is similar to the observation in the SST trial, where the surgeon noted subretinal or sub-RPE blood remaining in 154 eyes (93\%), including $42(25 \%)$ with $>4$ disc areas of blood..$^{20}$ Although in our patients postoperative subretinal haemorrhage was associated with an increased likelihood for subretinal fibrosis, there was no correlation to $\mathrm{CNV}$ recurrence.

About $50 \%$ of the eyes treated by laser photocoagulation for subfoveal CNV show recurrent CNV within 3 years. ${ }^{24}$ Similarly, a 24-month cumulative rate of $52 \%$ is reported after membrane extraction or limited translocation. In contrary, after full macular translocation, only about $8-10 \%$ of the patients sustain recurrent $\mathrm{CNV}^{25,26}$ Very late, between 6 and 12 months, 13 out of 30 patients demonstrated increasing leakage that was correlated to recurrent CNV formation in 11 patients. This is a rate of $37 \%$ of the eyes, intermediate between laser or membrane extraction and macular translocation. From the gathered information so far, one can speculate that the fovea exerts some attraction to CNV. Recurrence after laser occurs solely on the foveal side of the laser scar. Similarly, CNV recurrence after full macular translocation develops from the segment of the rim of choroid nearest to the translocated fovea. In our series, recurrences showed no preferred location. This may be explained by the central location of the fovea in relation to the rim of remaining choriocapillaris. The lesser rate of $\mathrm{CNV}$ recurrence compared with laser coagulation may be explained by the greater distance between the fovea and the remaining choriocapillaris and by a potential barrier effect of the transplanted Bruch's membrane within the patch. ${ }^{27,28}$ The much lower CNV recurrence rate of full macular transloction may be explained by the distance of the translocated fovea to the larger part of the remaining rim of choriocapillaris.

\section{Recommendations for case selection for patch translocation}

Wong et $a l^{29}$ have demonstrated for full macular translocation, that preoperative VA (20/120 or better) and lesion type (predominantly classic or submacular haemorrhage) is predictive for visual improvement. This is in accordance to our results indicating that patients benefit the most when the duration of the disease is shortest (probably in patients with classic or predominantly classic lesions and submacular haemorrhage). However, this result is in contradiction to others who report that macular rotation stabilizes or improves visual function irrespective of lesion size and composition. ${ }^{30}$ In the context of the current advances with anti-VEGF treatments ${ }^{1,2,31}$ (Joeres et al, unpublished), we now perform graft translocation only in patients not eligible for anti-VEGF medication. With respect to the results of the MARINA study it is not justified to not treat patients with wet AMD without large subretinal haemorrhage with ranibizumab or alternative preparations. ${ }^{2}$ Thus, patch surgery in the future may be an alternative to macular rotation for patients with recent large subretinal haemorrhages. Encouraging data on patch translocation in patients with geographic atrophy and recent visual loss warrant further follow-up. ${ }^{10}$

\section{Acknowledgements}

This paper was supported in part by the Deutsche Forschungsgemeinschaft (DFG) Jo 324/6-1 und 6-2 (Emmy Noether), Jo 324 /4-1, and Ki 743/5-1, and Ki 743 /2-1, the Brunnenbusch Stein Stiftung, the Glaser Stiftung and the RetinoVit Stiftung Köln. The authors have no proprietary interest in any of the materials used in this study.

\section{References}

1 Gragoudas ES, Adamis AP, Cunningham Jr ET, Feinsod M, Guyer DR, VEGF Inhibition Study in Ocular Neovascularization Clinical Trial Group. Pegaptanib for 
neovascular age-related macular degeneration. N Engl J Med 2004; 351: 2805-2816.

2 Rosenfeld PJ, Brown DM, Heier JS, Boyer DS, Kaiser PK, Chung CY et al, MARINA Study Group. Ranibizumab for neovascular age-related macular degeneration. $N$ Engl J Med 2006; 355(14): 1419-1431.

3 Blinder KJ, Bradley S, Bressler NM, Bressler SB, Donati G, Hao Y et al, : Treatment of Age-related Macular Degeneration with Photodynamic Therapy study group; Verteporfin in Photodynamic Therapy study group. Effect of lesion size, visual acuity, and lesion composition on visual acuity change with and without verteporfin therapy for choroidal neovascularization secondary to age-related macular degeneration: TAP and VIP report no. 1. Am J Ophthalmol 2003; 136: 407-418.

4 Thomas MA, Grand MG, Williams DF, Lee CM, Pesin SR, Lowe MA. Surgical management of subfoveal choroidal neovascularization. Ophthalmology 1992; 99: 952-968.

5 Scheider A, Gündisch O, Kampik A. Surgical extraction of subfoveal choroidal new vessels and submacular haemorrhage in age-related macular degeneration: results of a prospective study. Graefe's Arch Clin Exp Ophthalmol 1999; 237: 10-15.

6 Submacular Surgery Trial Research Group. Surgery for subfoveal choroidal neovascularization in age-realted macular degeneration. Ophthalmic findings: SST Report No.11. Ophthalmology 2004; 111: 1967-1980.

7 Peyman GA, Blinder KJ, Paris CJ, Alturki W, Nelson NC, Desai U. A technique for retinal pigment epithelium transplantation for age-related macular degeneration secondary to extensive subfoveal scarring. Ophthalmic Surg 1991; 22: 102.

8 Stanga PE, Kychenthal A, Fitzke FW, Halfyard AS, Chan R, Bird AC et al Retinal pigment epithelium translocation after choroidal neovascular membrane removal in age-related macular degeneration. Ophthalmology 2002; 109: 1492-1498.

9 van Meurs JC, Van Den Biesen PR. Autologous retinal pigment epithelium and choroid translocation in patients with exudative age-related macular degeneration: shortterm follow-up. Am J Ophthalmol 2003; 136: 688-695.

10 Joussen AM, Joeres S, Fawzy N, Heussen FM, Llacer H, van Meurs JC et al Autologous translocation of the choroid and RPE in age-related macular degeneration. Am J Ophthalmol 2007; 114: 551-560.

11 Lappas A, Weinberger AWA, Foerster AMH, Kube Th, Kirchhof B. Iris pigment epithelium translocation in age related macular degeneration. Graefes Arch Exp Clin Ophthalmol 2000; 238: 631-641.

12 Thumann G, Aisenbrey S, Schraermeyer U, Lafaut B, Esser P, Walter P et al Transplantation of autologous iris pigment epithelium after removal of choroidal neovascular membranes. Arch Ophthalmol 2000; 118: 1350-1355.

13 Lappas A, Foerster AM, Weinberger AW, Coburger S, Schrage NF, Kirchhof B. Translocation of iris pigment epithelium in patients with exudative age-related macular degeneration: long-term results. Graefes Arch Clin Exp Ophthalmol 2004; 242: 638-647.

14 Aisenbrey S, Lafaut BA, Szurman P, Hilgers RD, Esser P, Walter $\mathrm{P}$ et al Iris pigment epithelial translocation in the treatment of exudative macular degeneration: a 3-year follow-up. Arch Ophthalmol 2006; 124: 183-188.

15 Stifter E, Konig F, Lang T, Bauer P, Richter-Muksch S, Velikay-Parel $\mathrm{M}$ et al Reliability of a standardized reading chart system: variance component analysis, test-retest and inter-chart reliability. Graefes Arch Clin Exp Ophthalmol 2004; 242: 31-39.

16 Radner W, Willinger U, Obermayer W, Mudrich C, VelikayParel M, Eisenwort B. Eine neue Lesetafel zur gleichzeitigen Bestimmung von Lesevisus und Lesegeschwindigkeit. Klin Monatsbl Augenheilkd 1998; 213: 174-181.

17 Barbazetto I, Burdan A, Bressler NM, Bressler SB, Haynes L, Kapetanios AD et al, : Treatment of Age-Related Macular Degeneration with Photodynamic Therapy Study Group; Verteporfin in Photodynamic Therapy Study Group. Photodynamic therapy of subfoveal choroidal neovascularization with verteporfin: fluorescein angiographic guidelines for evaluation and treatment-TAP and VIP report No.2.. Arch Ophthalmol 2003; 121: 1253-1268.

18 Cahill MT, Mruthyunjaya P, Bowes Rickman C, Toth CA. Recurrence of retinal pigment epithelial changes after macular translocation with 360 degrees peripheral retinectomy for geographic atrophy. Arch Ophthalmol 2005; 123: 935-938.

19 MacLaren RE, Bird AC, Sathia PJ, Aylward GW. Long-term results of submacular surgery combined with macular translocation of the retinal pigment epithelium in neovascular age-related macular degeneration. Ophthalmology 2005; 112: 2081-2087.

20 Bressler NM, Bressler SB, Childs AL, Haller JA, Hawkins BS, Lewis $\mathrm{H}$ et al, Submacular Surgery Trials (SST) Research Group. Surgery for hemorrhagic choroidal neovascular lesions of age-related macular degeneration: ophthalmic findings: SST report no. 13. Ophthalmology 2004; 111: 1993-2006.

21 Mruthyunjaya P, Stinnett SS, Toth CA. Change in visual function after macular translocation with 360 degrees retinectomy for neovascular age-related macular degeneration. Ophthalmology 2004; 111: 1715-1724.

22 Aisenbrey S, Lafaut BA, Szurman P, Grisanti S, Luke C, Krott $\mathrm{R}$ et al Macular translocation with 360 degrees retinotomy for exudative age-related macular degeneration. Arch Ophthalmol 2002; 120: 451-459.

23 Hawkins BS, Bressler NM, Miskala PH, Bressler SB, Holekamp NM, Marsh MJ et al, Submacular Surgery Trials (SST) Research Group. Surgery for subfoveal choroidal neovascularization in age-related macular degeneration: ophthalmic findings: SST report no. 11. Ophthalmology 2004; 111: 1967-1980.

24 Macular Photocoagulation Study Group. Persistent and recurrent neovascularization after laser photocoagulation for subfoveal choroidal neovascularization of age-related macular degeneration. Arch Ophthalmol 1994; 112: 489-499.

25 Eckardt C, Eckardt U, Conrad HG. Macular rotation with and without counter-rotation of the globe in patients with age-related macular degeneration. Graefes Arch Clin Exp Ophthalmol 1999; 237: 313-325.

26 Abdel-Meguid A, Lappas A, Hartmann K, Auer F, Schrage $\mathrm{N}$, Thumann G et al One year follow up of macular translocation with 360 degree retinotomy in patients with age related macular degeneration. Br J Ophthalmol 2003; 87(5): 615-621.

27 Semkova I, Kreppel F, Welsandt G, Luther T, Kozlowski J, Janicki $\mathrm{H}$ et al Autologous transplantation of genetically modified iris pigment epithelial cells: a promising concept for the treatment of age-related macular degeneration and other disorders of the eye. Proc Natl Acad Sci USA 2002; 99: 13090-13095. 
28 Steele FR, Chader GJ, Johnson LV, Tombran-Tink J. Pigment epithelium-derived factor: neurotrophic activity and identification as a member of the serine protease inhibitor gene family. Proc Natl Acad Sci USA 1993; 90: 1526-1530.

29 Wong D, Stanga P, Briggs M, Lenfestey P, Lancaster E, Li KK et al Case selection in macular relocation surgery for age related macular degeneration. $\mathrm{Br}$ J Ophthalmol 2004; 88: 186-190.
30 Mruthyunjaya P, Stinnett SS, Toth CA. Impact of fluorescein angiographic characteristics of macular lesions on outcomes after macular translocation 360 degree surgery in eyes with age-related macular degeneration. Retina 2005; 25: 597-607.

31 Avery RL, Pieramici DJ, Rabena MD, Castellarin AA, Nasir MA, Giust MJ. Intravitreal bevacizumab (avastin) for neovascular age-related macular degeneration. Ophthalmology 2006; 113: 363-372.

Supplementary Information accompanies the paper on Eye website (http://www.nature.com/eye). 